\title{
High frequency oscillatory ventilation in the man- agement of a high output bronchopleural fistula: a case report
}

\author{
[L'utilisation de la ventilation oscillatoire à haute fréquence dans la prise en \\ charge d'une fistule bronchopleurale à débit élevé : une étude de cas]
}

Duc V. Ha MD, ${ }^{*}$ David Johnson $\mathrm{MD}^{*} \dagger$

Purpose: To describe the use of high frequency oscillatory ventilation (HFOV) in the management of a high output bronchopleural fistula (BPF).

Clinical features: A 55-yr-old female developed a BPF after thoracotomy and decortication of an empyema. The patient deteriorated on the second postoperative day $\left(\mathrm{pH} 7.10 \mathrm{PCO}_{2}\right.$ 89) requiring $100 \%$ oxygen and mechanical ventilation. After initial improvement, deterioration occurred by $24 \mathrm{hr}$ with conventional positive pressure ventilation (volume or pressure limited) because of decreased pulmonary compliance and bilateral diffuse airspace disease (acute respiratory distress syndrome), persistent increased peak and plateau airway pressures, a prolonged inspired oxygen concentration greater than 0.6 , and inability to apply positive end expiratory pressures because of an increased BPF leak (530 $\mathrm{mL} \cdot$ breaths $\left.^{-1}\right)$. HFOV was initiated and maintained for 28 days until resolution of the airspace disease and decreased leak through the BPF to $100 \mathrm{~mL} \cdot$ breaths $^{-1}$.

Conclusion: We report the successful use of HFOV in a patient with high output BPF. We suggest that HFOV is a useful technique in patients with a BPF when conventional positive pressure ventilation fails.

Objectif : Décrire l'usage de la ventilation oscillatoire à haute fréquence (VOHF) dans la prise en charge d'une fistule bronchopleurale $(F B P)$ à débit élevé.

Éléments cliniques : Une FBP s'est développée chez une femme de 55 ans à la suite d'une thoracotomie et de la décortication d'un empyème. L'état de la patiente s'est détérioré au deuxième jour postopératoire $\left(\mathrm{pH} 7,10 \mathrm{PCO}_{2} 89\right)$ et a nécessité l'utilisation d'oxygène à $100 \%$ et de ventilation mécanique. Une amélioration initiale a été notée, suivie d'une détérioration, 24 h après l'instauration de la ventilation traditionnelle à pression positive (pression ou volume limité), causée par une baisse de la compliance pulmonaire et un trouble alvéolaire diffus (syndrome de détresse respiratoire aiguë), la hausse de la pression de pointe et de la pression plateau des voies aériennes, la persistance d'une concentration d'oxygène inspirée plus grande que 0,6 et l'incapacité d'appliquer des pressions positives expiratoires à cause des fuites par la FBP (530 mL-respirations $\left.{ }^{-1}\right)$. La VOHF a été installée et maintenue pendant 28 jours jusqu'à la résolution du trouble respiratoire et la diminution de la fuite à $100 \mathrm{~mL} \cdot$ respirations ${ }^{-1}$.

Conclusion : L'efficacité de la VOHF chez une patiente qui présentait une FBP à débit élevé semble donc indiquer son utilité devant l'échec de la ventilation traditionnelle à pression positive en présence d'une FBP.

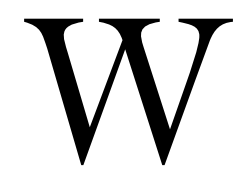

E report the novel use of high frequency oscillating ventilation (HFOV) in a patient with a high output bronchopleural fistula (BPF). BPF are communications between the bronchioles of the respiratory tract and pleural space usually caused by surgical trauma, lobectomy or pneumonectomy. BPF can also occur with infections such as tuberculosis, pneumonia, empyema or lung abscesses. BPF are especially problematic when positive pressure ventilation is required as tidal volume is preferentially delivered into the pleural space and not to alveoli. ${ }^{1,2}$ The

From the Department of Anesthesia, ${ }^{*}$ University of Saskatchewan, Saskatoon, Saskatchewan; and the Division of Critical Care Medicine, $\dagger$ University of Alberta, Edmonton, Alberta, Canada.

Address correspondence to: Dr. Duc V. Ha, Department of Anesthesiology, Royal University Hospital, 103 Hospital Drive, University of Saskatchewan, Saskatoon, Saskatchewan S7N 0W8, Canada. Phone: 306-655-1193; Fax 306-655-1279; E-mail: ducvinhha@hotmail.com Assessed September 24, 2002.

lst revision accepted March 13, 2003.

2nd revision accepted September 3, 2003. 
large air leak into the BPF may prevent the fistula from healing and results in inadequate tidal volume delivery to alveoli. As well, when large tidal volumes are delivered into the pleural space during conventional positive pressure ventilation, a tension pneumothorax can occur. $^{3}$ Although the incidence of BPF is low, anesthesiologists may encounter patients with a BPF during resuscitation for acute respiratory failure or in patients requiring surgery for BPF closure itself. ${ }^{4-21}$

\section{Case report}

A 55-yr-old woman with colon carcinoma underwent a left hemicolectomy. Six months later, metatastic disease involving the liver was noted which required a cholecystectomy and right hemihepatectomy. Two months later, she was re-admitted for drainage of a right pleural effusion. At that time, an empyema was diagnosed and the patient underwent a right thoracotomy with pleural decortication. An air leak from the chest tube continued for several days postoperatively. A BPF was diagnosed and surgically repaired. Postoperatively the patient was admitted to the intensive care unit (ICU) and received conventional positive pressure mechanical ventilation (Table). The maximum air leak from the chest tubes was approximately $160 \mathrm{~mL} \cdot$ breath $^{-1}$. The patient was extubated on the second postoperative day and returned to the ward requiring oxygen by face mask (Table). The patient was re-admitted to the ICU two days later and required mechanical ventilation due to respiratory distress, respiratory acidosis, and an inspired oxygen of $100 \%$. Although there was an initial improvement within $12 \mathrm{hr}$, at $24 \mathrm{hr}$ respiratory variables had deteriorated while on conventional positive pressure ventilation (volume or pressure limited). The chest radiograph revealed increased bilateral diffuse airspace disease (acute respiratory distress syndrome) and a large left-sided pleural effusion. The left-sided pleural effusion was drained without significant improvement in respiratory status. Conventional mechanical ventilation was deemed a failure 22,23 because of persistent increased peak and plateau airway pressures, a prolonged inspired oxygen concentration greater than 0.6 with inability to apply positive end-expiratory pressure (PEEP) because of an increased BPF leak (530 $\mathrm{mL} \cdot$ breath $^{-1}$ with a plateau airway pressure of $35 \mathrm{~cm}$ $\left.\mathrm{H}_{2} \mathrm{O}\right)$. HFOV was initiated at $3 \mathrm{~Hz}$, amplitude of 15 (dimensionless index), ${ }^{24}$ inspiratory time of $35 \%$, mean airway pressure of $25 \mathrm{~cm} \mathrm{H}_{2} \mathrm{O}$, and $\mathrm{FIO}_{2}$ of $100 \%$ with continued improvement over the subsequent $12 \mathrm{hr}$ (Table). A commercial HFO was used (Sensor Medics 3100A (pediatric) and 3100B (adult) SensorMedics Critical Care, Yorba Linda, CA, USA; www.sensormedics.com). The patient required 28 days of HFOV. After the initial day of HFOV, oxygenation was adequate with a $\mathrm{pO}_{2}$ of 80 to 100 mmHg with $\mathrm{FIO}_{2}$ varying from 35 to $60 \%$ and PEEP of zero. However, the patient periodically had problems with $\mathrm{CO}_{2}$ elimination; at the most extreme $\mathrm{pH}$ 7.15 and $\mathrm{pCO}_{2} 115 \mathrm{mmHg}$. The management of her respiratory acidosis included increasing the amplitude (15-40), decreasing respiratory frequency $(5-3 \mathrm{~Hz})$, decreasing the inspiratory time $(0.5-0.3 \mathrm{sec})$, removing endotracheal tube cuff seal (allowing for enhanced airflow during active expiration), paralysis (vecuronium), and sedation (morphine and lorazepam). The sequential institution of these therapies allowed the $\mathrm{pCO}_{2}$ to be maintained within the 45 to $70 \mathrm{mmHg}$ range. After 21 days in the ICU, the volume output from her chest tubes decreased to $100 \mathrm{~mL} \cdot$ breath $^{-1}$ (assessed during a brief interruption of high frequency ventilation; HFV), paralysis was stopped, and arterial blood gases showed a $\mathrm{pH} 7.38, \mathrm{pCO}_{2} 51 \mathrm{mmHg}$, $\mathrm{pO}_{2} 76 \mathrm{mmHg} \mathrm{HCO}_{3}{ }^{-} 28$ on $\mathrm{FIO}_{2} 35 \%$. The patient was switched to pressure controlled ventilation with tidal volume of $300 \mathrm{~mL}$, respiratory rate of 22, peak airway pressure of $15 \mathrm{~cm} \mathrm{H}_{2} \mathrm{O}$, and PEEP $4 \mathrm{~cm} \mathrm{H}_{2} \mathrm{O}$. A critical care myopathy was diagnosed by biopsy and presumed secondary to prolonged ICU stay and use of muscle relaxants. Pressure controlled ventilation was required for an additional 11 days before being able to discontinue mechanical ventilation. The patient was discharged from the ICU after 52 days and discharged home on the 138th day after admission.

\section{Discussion}

We report the successful use of $\mathrm{HFOV}$ in a patient who developed a high output BPF after a thoracotomy and decortication of an empyema and subsequent development of acute lung injury (adult respiratory distress syndrome) and the prolonged need for high inspired oxygen and persistent increased inspiratory pressures. $^{22,23}$ The change from pressure control ventilation to HFOV resulted in a decrease in the air flow across the BPF, lowered inspired oxygen concentration, and lowered inspiratory peak pressures. After a lengthy period of HFOV, the patient was safely returned to conventional ventilation and eventually weaned from mechanical ventilation.

A number of options were possible in providing artificial ventilation for this patient. Conceptually the problem was a high compliance conduit in the right lung with diversion of minute ventilation to the BPF and a low compliance, acute injured lung requiring higher inspiratory pressures for effective alveolar ventilation. The options that were available consisted of: 
1) Conventional volume or pressure limited ventilation with increased respiratory rate at low tidal volume to minimize peak inspiratory pres sure, increased total inspiratory time to decrease peak airway pressures, and minimized PEEP.

2) Timed occlusion of chest tubes to decrease BPF leak.

3) Dual lung ventilation with right and left bronchus isolation allowing for selective ventilation of the high and low compliance lung.

4) Non-conventional ventilation including high frequency jet ventilation or high frequency oscillation.

5) Extracorpeal oxygenation.

Measures to improve oxygenation with conventional mechanical ventilation such as prolonged inspiratory time, large tidal volumes, exhalation retard, PEEP, inspiratory pauses or reversal of the inspiratory to expiratory ratio also increase airway pressure and loss of tidal volume through the BPF. ${ }^{1}$ A number of modifications to conventional mechanical ventilation have been attempted in order to adjust for the loss of minute ventilation. Synchronized intermittent mandatory ventilation allows periodic spontaneous breaths, decreasing positive pressure and mean airway pressures. Pressure control ventilation (PCV) limits peak airway pressure decreasing air flow and pressure through the fistula and promoting its closure. ${ }^{2} \mathrm{~A}$ review of 39 cases of persistent $\mathrm{BPF}$ during mechanical ventilation (assist control in 33 patients and intermittent mandatory ventilation in six patients) revealed that only two patients developed respiratory acidosis unresponsive to conventional mechanical ventilation management. The authors concluded that BPF does not usually require special mechanical ventilation techniques. However, in the two patients who died, the air leak was greater than $500 \mathrm{~mL} \cdot$ breaths $^{-1}{ }^{3}$ as noted in this case report. In the patient we describe, effective minute ventilation was adequate for carbon dioxide elimination despite the large air leak. Oxygenation at lower inspired oxygen concentrations required greater alveolar recruitment by use of either higher peak or end expiratory pressure which would have the potential to worsen the acute lung injury or maintain high airflow through the BPF limiting the potential for closure. We considered conventional mechanical ventilation a failure for these reasons.

Ventilation can be improved by altering the BPF leak. The appropriate size chest tube must be inserted to allow adequate drainage of pleural air. Suction pressure varies exiting air flow (up to $20-35 \mathrm{~L} \cdot \mathrm{min}^{-1}$ ). ${ }^{19}$
High air removal may be necessary in order to prevent pneumothoraces but may result in difficulties maintaining an adequate tidal volume for gas exchange. There are a few case reports of synchronizing chest tube occlusion at the time of inspiration in mechanically ventilated patients. ${ }^{20,21}$ The goal is to limit loss of tidal volume on inspiration and limit air leak on expiration to allow healing of the BPF, maintain PEEP for oxygenation, and remove intrapleural air to minimize pneumothoraces. In this patient, we did not have the capacity to perform synchronized chest tube occlusion.

Independent lung ventilation is another option for positive pressure ventilation in patients with BPF. There have been many case successful reports of independent lung ventilation with a double lumen endotracheal tube. ${ }^{15-17}$ In these cases the unaffected lung had no pathology and unilateral conventional ventilation was sufficient for gas exchange. The affected lung with the BPF was ventilated via high frequency jet ventilation (HFJV) or independently ventilated with conventional positive pressure at a lower mean airway pressure. Independent ventilation with unilateral HFJV has been described when both conventional ventilation and HFJV have failed. ${ }^{18}$ We did not choose dual lung ventilation because of the difficulty in maintaining proper endobronchial tube placement for prolonged periods.

High frequency ventilation has been advocated in patients with BPF as a means of providing adequate gas exchange at lower mean airway pressures. $\mathrm{HFJV}^{5-8}$ uses gas under high pressure (15-50 psi) introduced through a small-bore cannula situated in the endotracheal tube. The jet pressure and duration of the inspiratory jet determine the volume of entrained gas. Thus the tidal volume is directly proportional to the jet pressure and inspiratory/expiratory ratio. HFJV generally delivers a tidal volume of 2 to $5 \mathrm{~mL} \cdot \mathrm{kg}^{-1}$ at a frequency of 100 to 200 breaths $\mathrm{min}^{-1}$. The small-bore gas cannula reduces visual obstruction in the airway which led to HFJV's popularity in rigid bronchoscopy. Because the high-velocity jet entrains air from the circuit, controlling tidal volume is difficult. Additionally, gas warming and humidification can be problematic in HFJV because the gas jet both expands and cools as it exits the high-pressure cannula. Suboptimal humidification and high gas-flow rates with HFJV may cause damage to the trachea and proximal airways. Expiration in HFJV is passive and gas trapping with its associated lung injury and hemodynamic complications can occur. In a series of seven patients with acute respiratory distress syndrome and $\mathrm{BPF}, \mathrm{HFJV}$ resulted in a decrease in $\mathrm{pO}_{2} / \mathrm{FIO}_{2}$ ratio from $227 \pm 167$ to $133 \pm 100$ and an increase in $\mathrm{pCO}_{2}$ from $47 \pm 13$ to $56 \pm 18 \mathrm{mmHg}^{4}$ In 
TABLE Description of respiratory variables

\begin{tabular}{|c|c|c|c|c|c|c|c|}
\hline & $\begin{array}{l}\text { Preoperative } \\
\text { day } 0\end{array}$ & $\begin{array}{l}\text { Operative } \\
\text { (first) day } 1 \\
\text { in ICU }\end{array}$ & $\begin{array}{l}\text { Post } \\
\text { operative } \\
\text { day } 2\end{array}$ & $\begin{array}{l}\text { Post } \\
\text { operative } \\
\text { day } 4\end{array}$ & $\begin{array}{l}\text { Post } \\
\text { operative } \\
\text { day } 4\end{array}$ & $\begin{array}{l}\text { Post } \\
\text { operative } \\
\text { day } 5\end{array}$ & $\begin{array}{l}\text { Post } \\
\text { operative } \\
\text { day } 5\end{array}$ \\
\hline Time & & & & 09:40 & $20: 40$ & 08:20 & 23:00 \\
\hline Mode of ventilation & Spontaneous & $\begin{array}{l}\text { CPAP } 5 \\
\text { pressure } \\
\text { support } 14\end{array}$ & Spontaneous & $\begin{array}{l}\text { Pressure } \\
\text { control } \\
\text { PEEP } 5\end{array}$ & $\begin{array}{l}\text { Pressure } \\
\text { regulated } \\
\text { volume control } \\
\text { PEEP } 8\end{array}$ & $\begin{array}{l}\text { Pressure } \\
\text { control } \\
\text { PEEP } 10\end{array}$ & $\mathrm{HFOV}$ \\
\hline Inspired oxygen fraction & 0.21 & 0.4 & 0.4 & 0.7 & 0.5 & 0.8 & 0.5 \\
\hline Respiratory rate breaths $\cdot \mathrm{min}^{-1}$ & 16 & 14 & 16 & 20 & 15 & 15 & $3 \mathrm{HZ}$ \\
\hline Minute ventilation (L) & & 8.5 & & 10 & 7.5 & 6.5 & \\
\hline Peak inspiratory pressure $\mathrm{cm} \mathrm{H}_{2} \mathrm{O}$ & & 14 & & 40 & 31 & 42 & 27 (mean) \\
\hline Tidal volume inspired $(\mathrm{mL})$ & & 500 & & 500 & 600 & 890 & \\
\hline Tidal volume expired (mL) & & 400 & & 400 & 500 & 370 & \\
\hline Broncho-pulmonary leak (mL) & & 100 & $\begin{array}{l}\text { not } \\
\text { quantified }\end{array}$ & 100 & 100 & 520 & $>500$ \\
\hline \multicolumn{8}{|l|}{ Arterial blood gases } \\
\hline $\mathrm{pH}$ & & 7.34 & 7.38 & 7.12 & 7.43 & 7.33 & 7.32 \\
\hline $\mathrm{PO}_{2} \mathrm{mmHg}$ & & 96 & 78 & 117 & 82 & 52 & 85 \\
\hline $\mathrm{PCO}_{2} \mathrm{mmHg}$ & & 44 & 24 & 81 & 32 & 46 & 42 \\
\hline Saturation & $95 \%$ & $99 \%$ & $97 \%$ & $100 \%$ & $98 \%$ & $89 \%$ & $98 \%$ \\
\hline
\end{tabular}

$\mathrm{CPAP}=$ continuous positive airway pressure $\left(\right.$ in $\left.\mathrm{cm} \mathrm{H}_{2} \mathrm{O}\right) ; \mathrm{PEEP}=$ positive end-expiratory pressure $\left(\right.$ in $\left.\mathrm{cm} \mathrm{H}_{2} \mathrm{O}\right)$; $\mathrm{HFOV}=$ high frequency oscillatory ventilation.

our institution, a commercial HFJV was not available so we did not choose the mode of ventilation as routine safety alarms and gas humidification would have been forfeited.

HFOV is another form of HFV. HFOV are airway vibrators producing little, if any, bulk gas delivery. A continuous flow of fresh gas provides inspired gas and clears $\mathrm{CO}_{2}$ from the system. Pressure oscillations in the airway produce tiny tidal volumes around a constant mean airway pressure. Tidal volume is determined by the amplitude of the airway pressure oscillations, which are determined by the stroke of the device that produces the oscillations. During HFOV, inspiration and expiration are active.

The benefits of HFOV include active expiration which decreases the risk of air trapping, over distension of airspaces, and circulatory depression. In neonates $\mathrm{CO}_{2}$ elimination was so efficient with $\mathrm{HFOV}$ that the risk of hypocarbia and cerebral ischemia was a concern. ${ }^{9}$ There have been several successful case reports of HFOV in adult patients with acute respiratory distress syndrome. ${ }^{10-12}$ The advantages of $\mathrm{HFO}$ with respect to volume control and gas conditioning may make it well suited to lung-protective mechanical ventilation in patients with acute lung injury. ${ }^{24,25}$ However, there are no reported cases of HFOV in patients with high output BPF. In the patient we describe, HFOV was used because there was both acute lung injury and a high output BPF.

There are many theories to explain the mechanism of gas exchange during HFV: ${ }^{13,14}$ l) gas transport occurs via direct bulk flow through the most proximal alveoli. 2) Longitudinal dispersion is gas exchange from turbulent flow when convective flow is superimposed on diffusion. 3) Fresh gas mixes with gas from the alveoli increasing the amount of gas from simple bulk flow. 4) Air flow is not uniform but varies with regional airway resistance and compliance. 5) Air moving through an airway under laminar flow is parabolic. The air closest to the bronchial wall has a lower velocity than air in the centre. With repeated respiratory cycles, gas in the centre of the airway advances further into the lung while gas on the margin moves out towards the mouth. 6) The heart beat contributes to gas mixing. 7) Molecular diffusion plays an important role in mixing of air. The relative contribution of each of these in this case report is unknown.

This patient with a large BPF air leak using conventional mechanical ventilation also needed high delivered oxygen concentration and PEEP because of diffuse airspace disease. The patient was oxygenated successfully using HFOV at lower oxygen concentration, lower mean airway pressures, and less air leak, but alveolar ventilation was insufficient and hypercarbia occurred. 
Although the patient was treated successfully using HFOV, the benefits of this therapy vs other available techniques remain speculative. As well, the use of HFOV in patients with isolated BPF and normal lung compliance or a low output BPF is unknown.

Resuscitative and intraoperative management of BPF with airspace disease may prove difficult. Currently, HFOV do not have the capability of providing volatile anesthetics, possibly limiting their utility in the operating room. Dual lung ventilation may require the addition of a second ventilator in the operating room and migration of the endobronchial tube may result in loss of lung isolation. Conventional operating room anesthetic machines have the capability to minimize inspiratory time and tidal volumes, provide for spontaneous or pressure regulated ventilation. However, this method may fail in BPF with a large air leak.

In the absence of randomized trials demonstrating the superiority of HFOV, we do not recommend HFOV as first line therapy for BPF given the general unfamiliarity with this technique and a high success rate with conventional mechanical ventilation. HFOV represents a secondary option after failure of conventional ventilation in patients with a high output BPF especially with a low compliance lung because of diffuse airspace disease. We believe that HFOV may represent an alternative to independent lung ventilation which has been the historical default but technically difficult to maintain over a prolonged period of time.

\section{References}

1 Powner DJ, Grenvik A. Ventilatory management of lifethreatening bronchopleural fistulae. A summary. Crit Care Med 1981; 9: 54-8.

2 Litmanovitch M, Joynt GM, Cooper PJF, Kraus P. Persistent bronchopleural fistula in a patient with adult respiratory distress syndrome. Treatment with pressurecontrolled ventilation. Chest 1993; 104: 1901-2.

3 Pierson DJ, Horton CA, Bates PW. Persistent bronchopleural air leak during mechanical ventilation. A review of 39 cases. Chest 1986; 90: 321-3.

4 Bishop MJ, Benson MS, Sato P, Pierson DJ. Comparison of high-frequency jet ventilation with conventional mechanical ventilation for bronchopleural fistula. Anesth Analg 1987; 66: 833-8.

5 Vincken W, Cosio MG. Clinical applications of high-frequency jet ventilation. Intensive Care Med 1984; 10: 275-80.

6 Rubio JJ, Algora-Weber A, Dominguez-de Villota E, Chamorro C, Mosquera JM. Prolonged high-frequency jet ventilation in a patient with bronchopleural fistula. An alternative mode of ventilation. Intensive Care Med 1986; 12: 161-3.
7 Roth MD, Wright JW, Bellamy PE. Gas flow through a bronchopleural fistula. Measuring the effects of highfrequency jet ventilation and chest-tube suction. Chest 1988; 93: 210-3.

8 Campbell D, Steinmann M, Porayko L. Nitric oxide and high frequency jet ventilation in a patient with bilateral bronchopleural fistula and ARDS. Can J Anesth 2000; 47: 53-7.

9 Riphagen $S$, Bohn D. High frequency oscillatory ventilation. Intensive Care Med 1999; 25: 1459-62.

10 Brambrink AM, Brachlow J, Weiler N, et al. Successful treatment of a patient with ARDS after pneumonectomy using high-frequency oscillatory ventilation. Intensive Care Med 1999; 25: 1173-6.

11 Varkul MD, Stewart TE, Lapinsky SE, Ferguson ND, Mehta S. Successful use of combined high-frequency oscillatory ventilation, inhaled nitric oxide, and prone positioning in the acute respiratory distress syndrome. Anesthesiology 2001; 95: 797-9.

12 Mehta S, Lapinsky SE, Hallett DC, et al. Prospective trial of high-frequency oscillation in adults with acute respiratory distress syndrome. Crit Care Med 2001; 29: 1360-9.

13 Krishnan JA, Brower RG. High-frequency ventilation for acute lung injury and ARDS. Chest 2000; 118 : 795-807.

14 Smith $R B$. Ventilation at high respiratory frequencies. High frequency positive pressure ventilation, high frequency jet ventilation and high frequency oscillation. Anaesthesia 1982; 37: 1011-8.

15 Feeley TW, Keating D, Nishimura T. Independent lung ventilation using high-frequency ventilation in the management of a bronchopleural fistula.

Anesthesiology 1988; 69: 420-2.

16 Benjaminsson E, Klain M. Intraoperative dual-mode independent lung ventilation of a patient with bronchopleural fistula. Anesth Analg 1981; 60: 118-9.

17 Mortimer AJ, Laurie PS, Garrett H, Kerr JH. Unilateral high frequency jet ventilation. Reduction of leak in bronchopleural fistula. Intensive Care Med 1984; 10: 39-41.

18 Crimi G, Candiani A, Conti G, Mattia C, Gasparetto $A$. Clinical applications of independent lung ventilation with unilateral high-frequency jet ventilation (ILVUHFJV). Intensive Care Med 1986; 12: 90-4.

19 Baumann MH, Sabn SA. Medical management and therapy of bronchopleural fistulas in the mechanically ventilated patient. Chest 1990; 97: 721-8.

20 Chaddouk EG. Bronchopleural fistula and mechanical ventilation: a simple technique of management? J Thorac Cardiovasc Surg 1995; 110: 1141-3.

21 Gallagher TJ, Smith RA, Kirby RR, Civetta JM. Intermittent inspiratory chest tube occlusion to limit 
bronchopleural cutaneous airleaks. Crit Care Med 1976; 4: 328-32.

22 Anonymous. Ventilation with lower tidal volumes as compared with traditional tidal volumes for acute lung injury and the acute respiratory distress syndrome The Acute Respiratory Distress Syndrome Network. N Engl J Med 2000; 342: 1301-8.

23 Parker JC, Hernandez LA, Peevy KJ. Mechanisms of ventilator-induced lung injury. Crit Care Med 1993; 21: 131-43.

24 Singh JM, Stewart TE. High-frequency mechanical ventilation principles and practices in the era of lung-protective ventilation strategies. Resp Care Clin N Am 2002; 8: 247-60.

25 Mehta $S$, MacDonald R. Implementing and troubleshooting high-frequency oscillatory ventilation in adults in the intensive care unit. Resp Care Clin N Am 2001; 7: 683-95. 